\title{
FUNDAMENTOS DEL PROCESAMIENTO DE IMÁGENES DIGITALES UTILIZANDO LA INTERFAZ DE USUARIO WEB OCTAVE-ONLINE
}

\author{
Pedro HUAMANÍ NAVARRETE \\ Universidad Ricardo Palma \\ phuamani@urp.edu.pe
}

\section{RESUMEN}

Este artículo describe los fundamentos del procesamiento digital de imágenes digitales haciendo uso de una interfaz de usuario web, de acceso libre, denominado Octave-Online. Dicha interfaz es parte de las aplicaciones de software del sistema operativo GNU, así como también es conocida como el equivalente al Matlab en versión libre; por esta razón, se eligió esta herramienta con la finalidad de dar un enfoque práctico del uso de diez técnicas básicas de procesamiento espacial de imágenes digitales. Para ello, se comenzó recopilando 8 archivos con contenidos de imágenes en JPG y con distintas características propias tales como alto y bajo contraste, alta y baja frecuencia, tonos de gris, e intensidad de colores, para poner en práctica las técnicas de procesamiento propuestas. Posteriormente, se proporcionaron algunas pautas para el acceso, subida de archivos JPG, creación de archivos de extensión *.m, y conocimiento de ciertas herramientas que ofrece la interfaz de usuario web Octave-Online. Luego, se procedió a implementar el código de programación utilizando un grupo de comandos, para el grupo de las 10 técnicas desarrolladas en dicha interfaz; así tenemos, binarización, negativo, conversión de formatos de color y gris, transformaciones geométricas, manipulación del histograma y filtrado espacial. Finalmente, se presenta una aplicación práctica del efecto Chroma Key utilizando una combinación de las técnicas de procesamiento espacial desarrolladas.

\section{PALABRAS CLAVES}

Octave-Online, imágenes digitales, archivos JPG, procesamiento espacial.

\section{DIGITAL IMAGE PROCESSING FUNDAMENTALS USING THE OCTAVE-ONLINE WEB USER INTERFACE}

\section{ABSTRACT}

This article describes the fundamentals of digital image digital processing using a free-access, web user interface called Octave-Online. This interface is part of the GNU operating system software applications, as well as it is known as the equivalent of Matlab in free versión; for this reason, this tool was chosen in order to give a practical approach to the use of ten basic techniques of spatial processing of digital images. To do this, we started by collecting 8 files with image contents in JPG and with different characteristics such as high and low contrast, high and low frequency, 
shades of gray, and intensity of colors, to put the proposed processing techniques into practice. Subsequently, some guidelines were provided for access, upload of JPG files, creation of * .m extension files, and knowledge of certain tools offered by the Octave-Online web user interface. Then, the programming code was implemented using a group of commands, for the group of the 10 techniques developed in said interface; thus we have, binarization, negative, conversion of color and gray formats, geometric transformations, histogram manipulation and spatial filtering. Finally, a practical application of the chroma key effect is presented using a combination of the developed spatial processing techniques.

\section{KEYWORDS}

Octave-Online, digital images, JPG files, spatial processing.

Recibido: $18 / 03 / 2020$

Aprobado: 30/04/2209

\section{INTRODUCCIÓN}

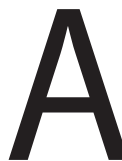

ctualmente, las herramientas computacionales para el cálculo numérico se han convertido en uno de los principales apoyos en la educación científica, y esto se debe a que otorgan facilidad en términos de representaciones gráficas $2 \mathrm{D}$ y $3 \mathrm{D}$, animaciones, rutinas de programación lógica, interfaces gráficas de usuario, operaciones simbólicas, operaciones numéricas y otras características más [1]. Asimismo, con la finalidad de facilitar tanto al estudiante como al docente el uso de herramientas computacionales de libre acceso para el desarrollo de las clases o de trabajos de investigación, se eligió la interfaz de usuario web Octave-Online como la más apropiada porque permite su acceso desde cualquier computador o laptop así como desde un dispositivo móvil o tablet.

\section{METODOLOGÍA DESARROLLADA}

La metodología presenta tres etapas: i) Búsqueda y recopilación de archivos de imágenes digitalizadas, cumpliendo ciertas características de resolución y codificación. ii) Acceso a la Interfaz de Usuario Web Octave-Online, desde internet y con una cuenta de correo electrónico, y iii) Desarrollo de las técnicas de procesamiento básico espacial de imágenes.

\section{1) Búsqueda y recopilación de archivos}

Para llevar a cabo la demostración de algunas técnicas de procesamiento básico espacial de imágenes digitales, se recurrió a internet para buscar y recopilar un 
grupo de archivos con extensión JPG y con una resolución próxima a 200×300 pixeles, para ser leídos y procesados desde la interfaz de usuario web OctaveOnline. Pues, dicha interfaz presenta limitaciones en cuanto a la resolución de las imágenes. De esta manera, se eligieron 8 tipos de imágenes con extensión JPG y con diferentes características como tonos de gris, alta luminosidad, variedad de colores, entre otras. A continuación, las figuras 1, 2, 3 y 4, muestran las imágenes elegidas para este propósito, con sus respectivas resoluciones y el enlace de internet de donde fueron obtenidas.

Respecto a la figura 3 de la izquierda, se realizó una manipulación de la resolución con la finalidad que sea posible el uso de esta; por lo cual, con apoyo de la aplicación PAINT del Windows, se cambió el tamaño de la imagen original reduciéndolo a un $60 \%$. Esto dio como resultado una resolución de $675 \times 450$ pixeles. Posteriormente, se retiraron algunas filas y columnas hasta alcanzar la resolución de 640×428 pixeles.
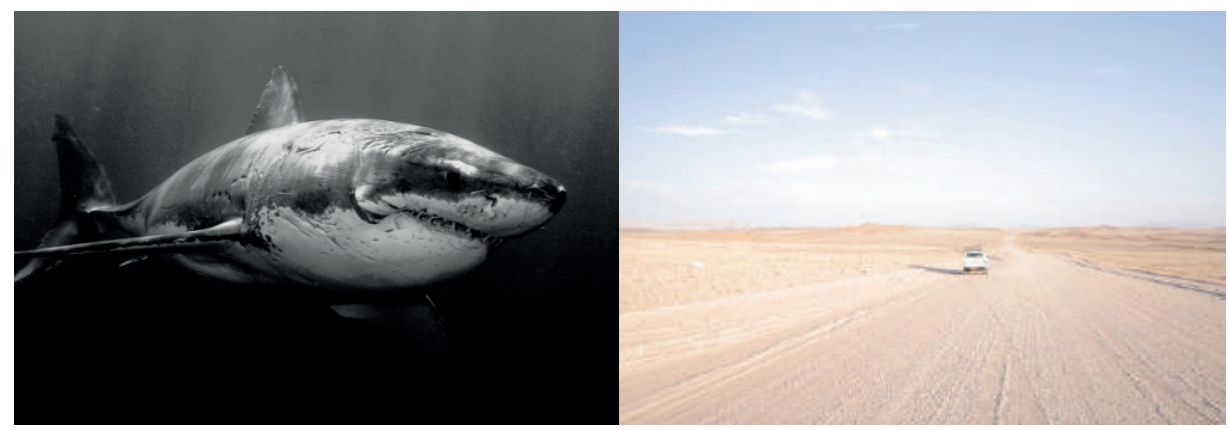

Figura 1. Izquierda: Fotografía en escala o tono de gris. Resolución de 800×500 pixeles [2]. Derecha: Fotografía de una carretera con bajo contraste. Resolución de $512 \times 342$ pixeles [3].

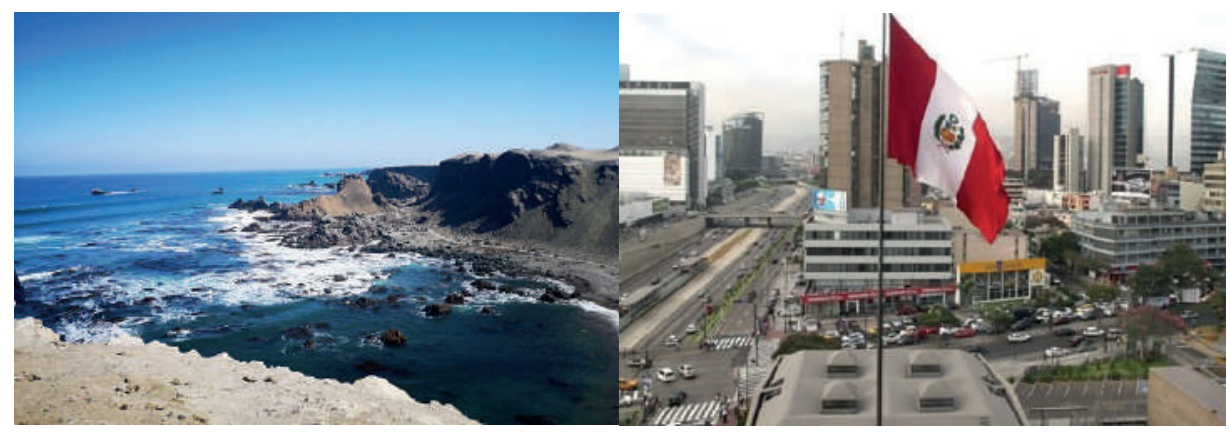

Figura 2. Izquierda: Fotografía de una playa de Marcona en Ica-Perú. Resolución de 1024x768 pixeles [4]. Derecha: Fotografía de la Plaza de Armas de Lima-Perú. Resolución de 640x480 pixeles [5]. 


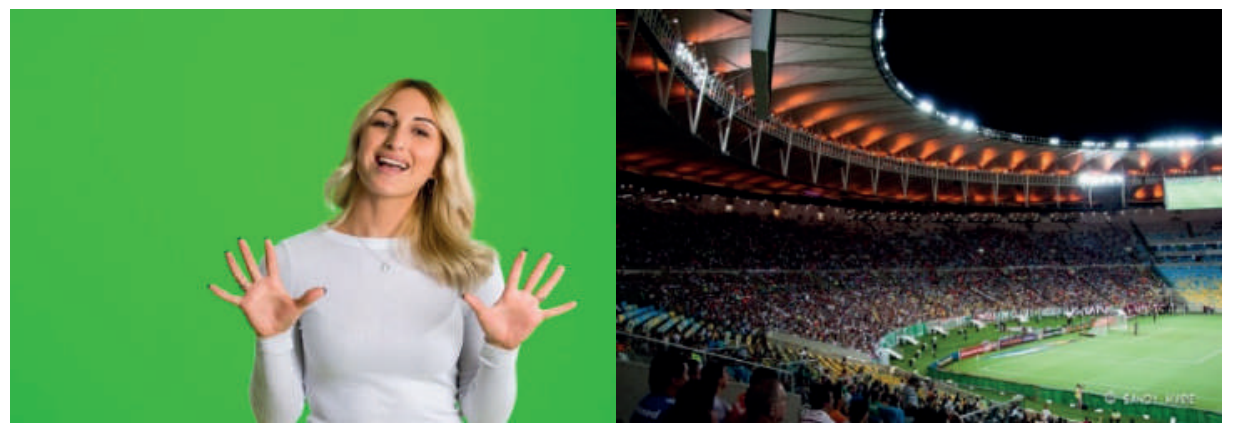

Figura 3. Izquierda: Fotografía de una mujer con fondo verde, resolución de $1125 \times 750$ pixeles [6]. Derecha: Fotografía nocturna del estadio Maracaná en Brasil, resolución de $640 \times 428$ pixeles [7].

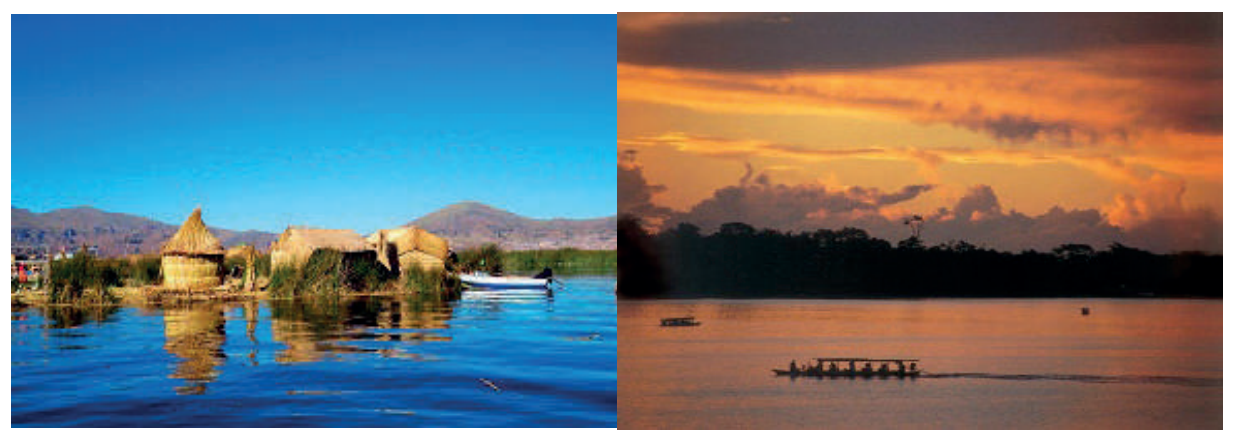

Figura 4. Izquierda: Fotografía diurna del Lago Titicaca - Perú, resolución de $640 \times 400$ pixeles [8]. Derecha: Fotografía nocturna de un río en lquitos-Perú, resolución de $924 \times 530$ pixeles [9].

\section{2) Acceso a la Interfaz de Usuario Web Octave-Online}

Para acceder a la Interfaz de Usuario Web Octave-Online, se recurre al buscador Google y se digita: "octave online". Como resultado de dicha búsqueda se obtiene el link: https://octave-online.net/ (Octave Online - Cloud IDE compatible with MATLAB) el cual permite ingresar a la interfaz en mención. A continuación, se muestran algunos conceptos que se encuentran relacionados con esta interfaz, así como el procedimiento a seguir para utilizar una cuenta de correo electrónico, subir archivos, crear archivos de programación, entre otros aspectos más.

2.1). GNU Octave: lenguaje de programación científico con sintaxis orientada a las matemáticas, con herramientas integradas de trazado y visualización. Además, es un software de distribución gratuito que se ejecuta en GNU/ Linux, macOS, BSD (Berkeley Software Distribution), es compatible con muchos scripts de software de computación digital de Matlab [10], es 
conocido como el equivalente al Matlab libre, y es parte de las aplicaciones de software del sistema operativo GNU.

2.2). Interfaz de Usuario Web Octave-Online: plataforma digital y robusta, a la que se accede directamente desde la web o internet, lo que permite una interacción directa y fácil con el usuario [1]. La figura 5 muestra una captura de pantalla obtenida al ingresar a la interfaz de usuario web Octave-Online, con un menú ubicado en la parte superior-derecha que permite acceder a través de una cuenta de correo electrónico, a algunas herramientas como por ejemplo cargar y descargar archivos de imágenes para el procesamiento, crear archivos con extensión *.m para almacenar el código de programación, cambiar el nombre, refrescarlos, borrarlos, imprimirlos, guardarlos, entre otras más. Una vez que se haya logrado el acceso, la interfaz de usuario se presenta tal como se observa en la figura 6; y como se aprecia, varias zonas han sido señaladas con una enumeración del 1 al 5. i) Zona 1: corresponde a la lista de archivos de distintas extensiones como *.m, ${ }^{*}$.jpg, ${ }^{*}$.mat, ${ }^{*}$.wav, etc, que el usuario de la cuenta de correo electrónico ha cargado. ii) Zona 2: corresponde a la ventana donde se aprecia el código de programación contenido en algunos de los archivos de extensión *.m. iii) Zona 3: permite visualizar el nombre y la dimensión de todas las variables que se vienen utilizando. iv) Zona 4: representa el acceso a la línea de comandos. v) Zona 5: algunas herramientas para los archivos propios.

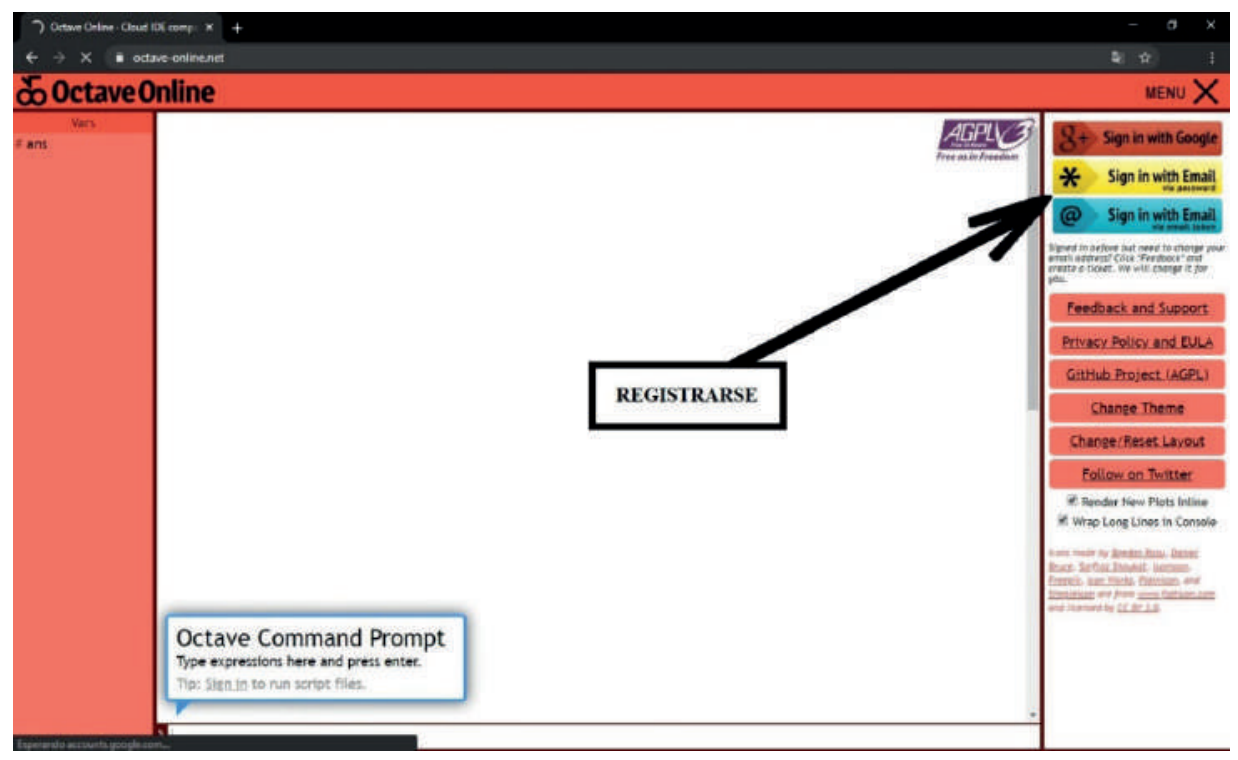

Figura 5. Captura de pantalla de la interfaz de usuario web Octave Online [10]. 


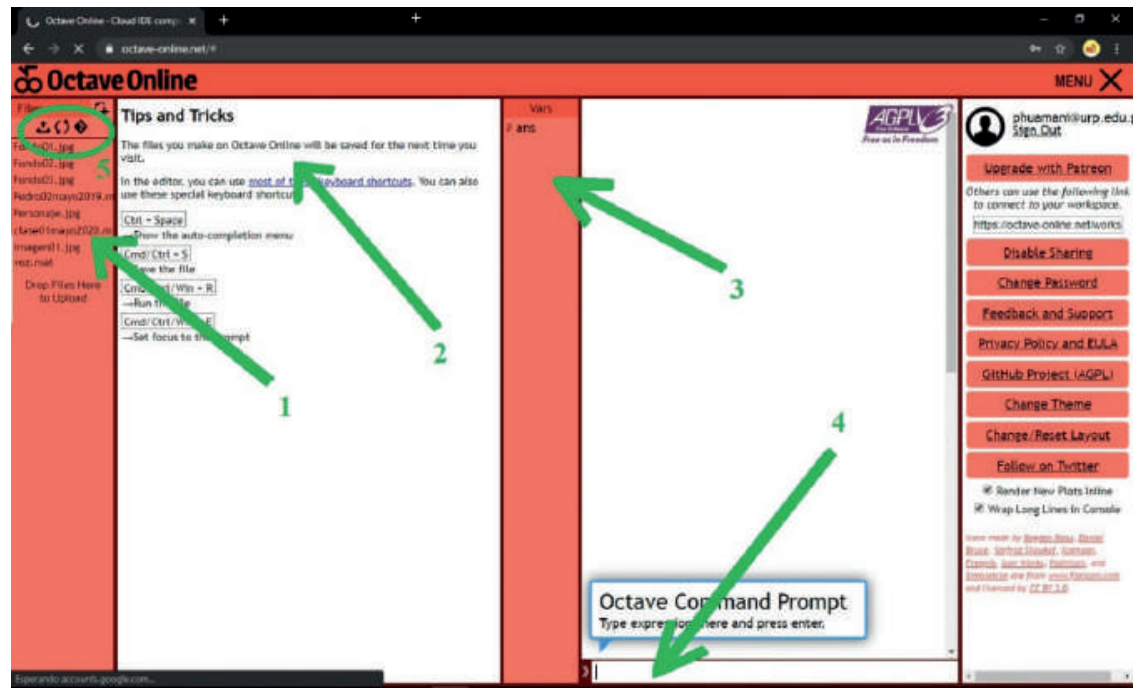

Figura 6. Captura de pantalla de la interfaz de usuario web Octave-Online accedido a través de una cuenta de correo electrónico [10].

2.3). Proceso de carga y creación de archivos: tanto el procedimiento de carga o subida de archivos y la creación de los mismos en la interfaz de usuario web Octave-Online, es básicamente dirigirse a las opciones que se muestran en la barra de herramientas del lado izquierdo superior de dicha interfaz. En cuanto a la carga o subida de archivos, una vez hecho click en la opción UPLOAD FILE se da acceso a la ventana del explorador de Windows y desde ahí es posible elegir arbitrariamente el archivo deseado; asimismo, es posible cargar archivos a través de una operación de arrastre. Mientras que, para crear un nuevo archivo de extensión *.m, se debe hacer click en la opción CREATE EMPTY FILE; esto permitirá asignar un nombre al archivo desde una ventana emergente. A continuación, en la figura 7 se visualiza la ubicación de las opciones anteriormente comentadas.

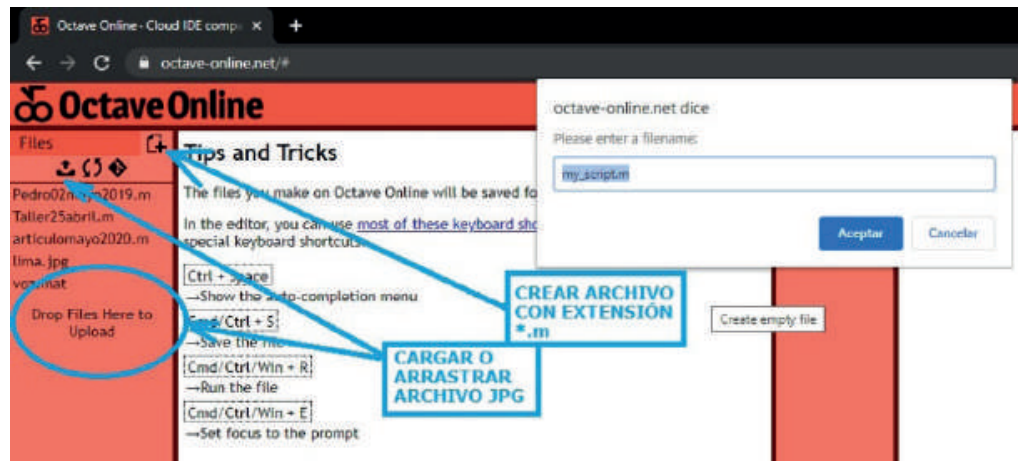

Figura 7. Parte de la captura de pantalla del Octave-Online para mostrar las opciones de crear, arrastrar y cargar o subir archivos [10]. 


\section{3) Desarrollo de las técnicas de procesamiento básico espacial de imágenes}

Solamente se abordaron 10 técnicas de procesamiento básico espacial de imágenes con la finalidad de no extender el contenido de este artículo, y asimismo sea el suficiente para demostrar el uso de esta interfaz en el campo del procesamiento básico y espacial de imágenes digitales.

3.1). Lectura y visualización de archivos JPG. Es el primero que se realiza con la finalidad de leer/abrir y visualizar las imágenes que serán procesadas a través de la interfaz de usuario web Octave-Online; previo a este paso se asume que las imágenes fueron cargadas a través de una cuenta de correo electrónico. Por lo cual, se procedió a utilizar el comando IMREAD para abrir dos de los archivos JPG y asignar el contenido de estos a dos variables del tipo arreglo; para luego, visualizarlos a través del comando IMSHOW. Sin embargo, al realizar dicho procedimiento, la interfaz de usuario web Octave-Online dio el siguiente mensaje: "Maximum allowable length is 1000000 bytes", esto obligó a manipular nuevamente la resolución de cada uno de las imágenes contenidas en los archivos JPG. Por lo cual, con apoyo de la aplicación PAINT del Windows, se procedió a una reducción equivalente a un $50 \%$ (cuarta parte); por ejemplo, en el caso de la imagen de la figura 2 de la izquierda presentaba una resolución de 1024x768 y después de reducirla pasó a tener $256 \times 192$. A continuación, en la figura 8 se muestra parte de la captura de pantalla del procedimiento de lectura y visualización de cuatro archivos JPG con sus nuevas resoluciones.

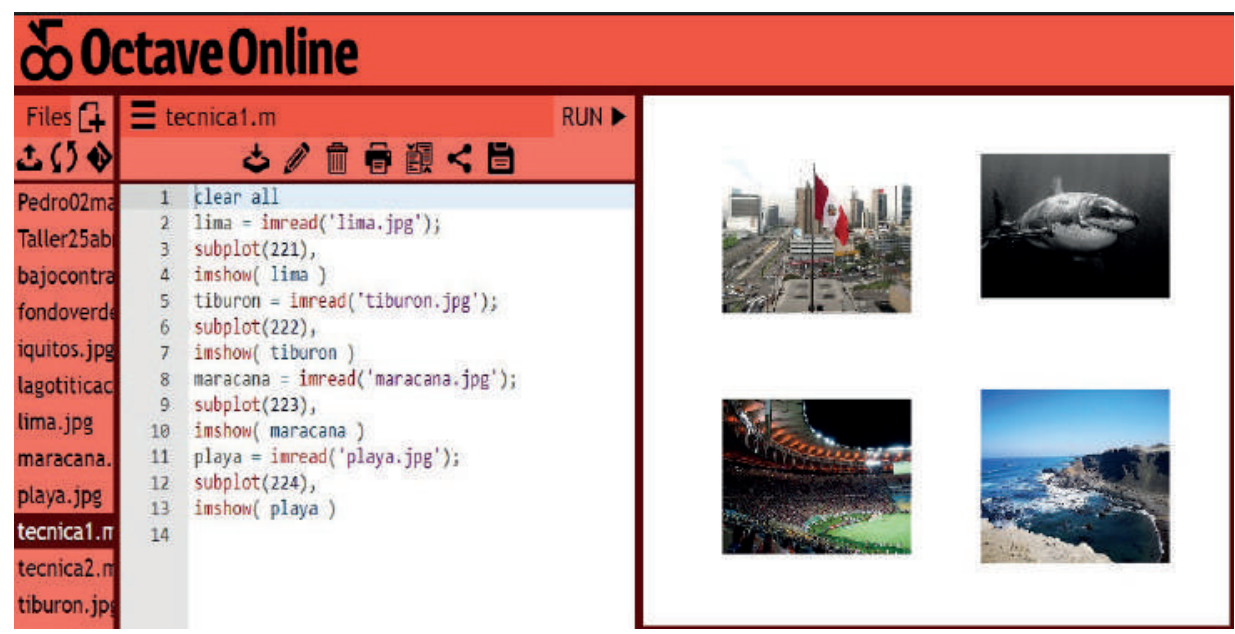

Figura 8. Lectura y visualización de archivos JPG con Octave-Online. Fuente: Elaboración propia.

3.2). Transformación de color a gris. Por lo general, las imágenes en la web se encuentran en formato de color. Por lo tanto, para transformarlas a un formato de gris se utilizó la función RGB2GRAY. La figura 9 muestra parte de la captura de pantalla del procedimiento de conversión de formato de color a gris, para dos archivos JPG. 
3.3). Transformación de gris a blanco/negro. Para transformar las imágenes de un formato de gris a blanco/negro es necesario elegir un umbral que se encuentre situado en la franja dinámica de la imagen de gris; es decir, si la imagen fue codificada con 8 bits/pixel el umbral elegido debe encontrarse entre 0 y $2^{8}-1$. Por lo tanto, para realizar tal operación se utilizaron las funciones GRAYTHRESH (para elegir el umbral) e IM2BW (para hacer la transformación a blanco/negro). A continuación, en la figura 10 se muestra parte de la captura de pantalla del procedimiento de conversión de formato de gris a blanco/negro, para dos archivos JPG.

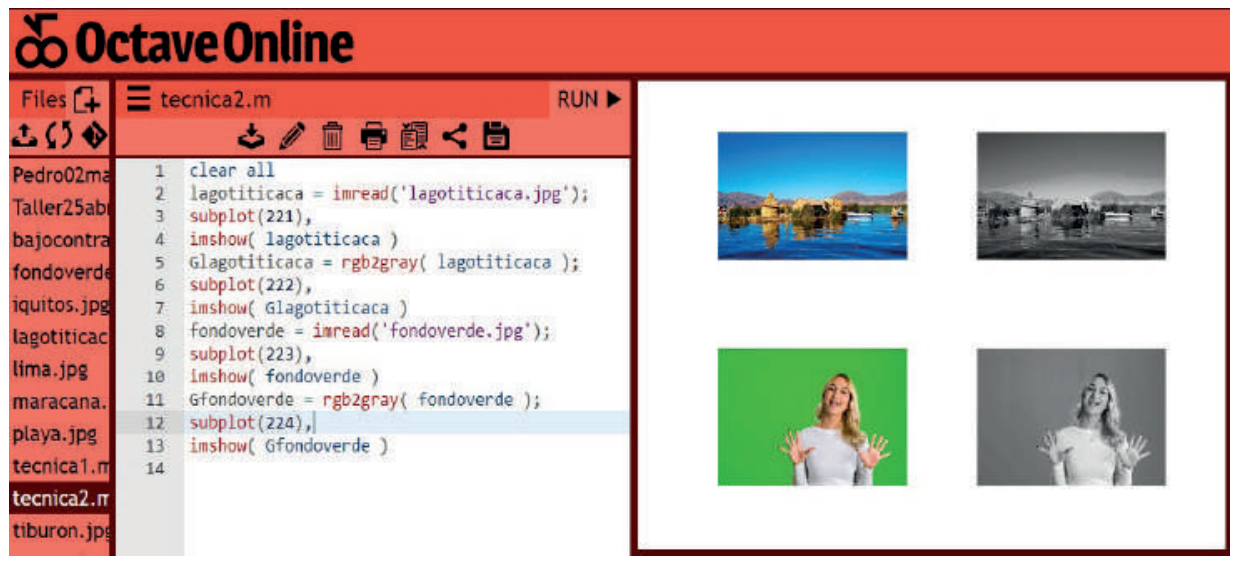

Figura 9. Transformación de color a gris con Octave-Online. Fuente: Elaboración propia.

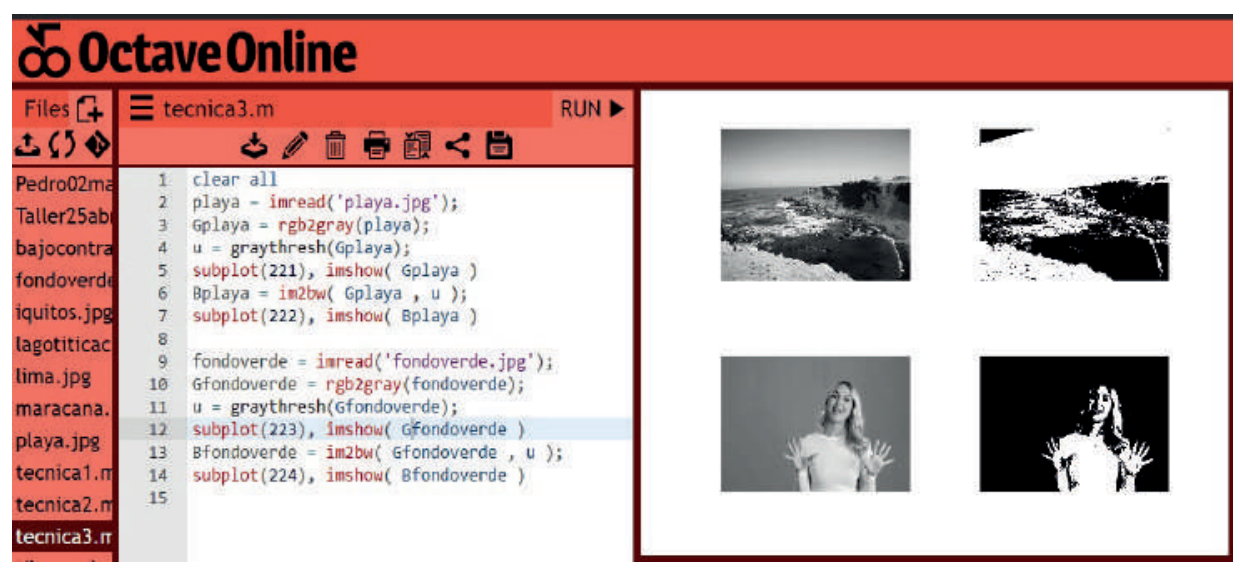

Figura 10. Transformación de gris a blanco/negro con Octave-Online. Fuente: Elaboración propia.

3.4). Negativo de imágenes de color, gris y blanco/negro. La obtención del negativo se logra a partir de una operación de substracción donde una constante (por ejemplo 255 o 1 dependiendo de la codificación de bits/ pixel) representa al minuendo, mientras que la propia imagen representa 
al sustraendo. A continuación, en la figura 11 se muestra parte de la captura de pantalla del procedimiento de obtención del negativo para una imagen de color, gris y blanco/negro de un archivo JPG.

3.5). Representación de imagen de color en tono verde y azul. El uso del comando IMREAD en archivos de imágenes a color en JPG, permite representarlos por una variable tipo arreglo MxNx3 utilizando el modelo de color RGB; de esta manera, tal variable contiene los tres canales de color: Rojo, Verde y Azul y es posible separarlos y visualizarlos en un canal individual; para ello, se elige solo uno de los canales de interés y se inserta en una nueva variable tipo arreglo definida previamente con valores iguales a cero. La figura 12 muestra el procedimiento para la representación de un solo canal de color (verde y azul).

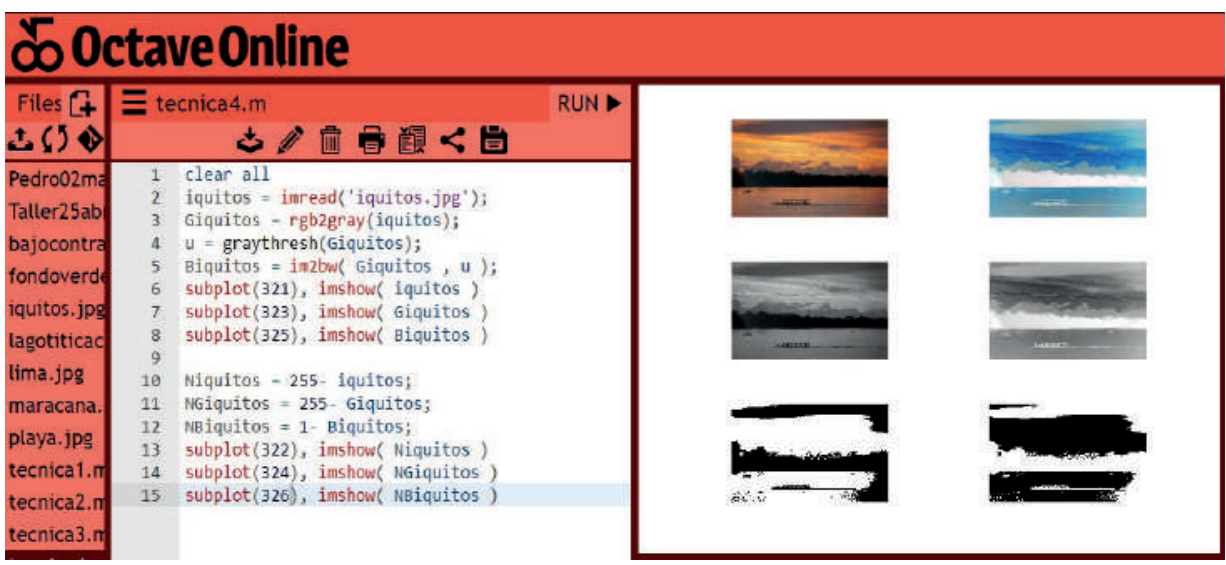

Figura 11. Obtención del negativo para una imagen de color, gris y blanco/negro con Octave-Online.

Fuente: Elaboración propia.

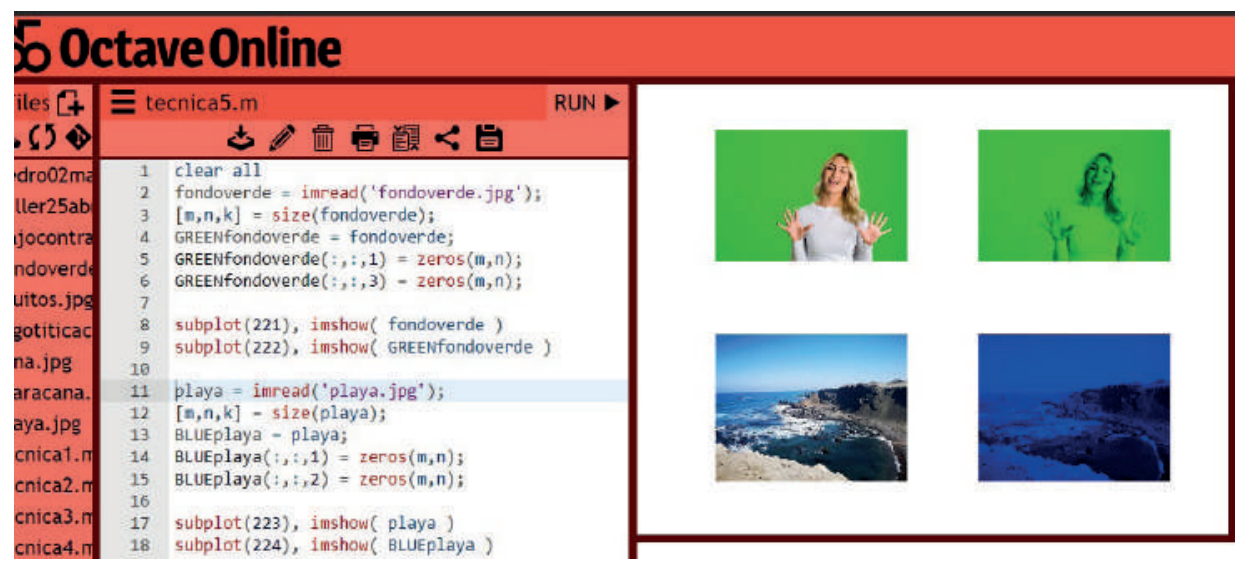

Figura 12. Representación de un solo canal de color (Verde y Azul) en dos imágenes de color, utilizando Octave-Online.

Fuente: Elaboración propia. 
3.6). Transformaciones geométricas: giro y mirror. Para realizar la transformación geométrica de giro se recurre al comando FLIPLR que permite girar de izquierda a derecha sobre el eje vertical, todas las columnas de la variable tipo arreglo que representa al archivo leído. Y, por otro lado, para realizar la transformación geométrica mirror, se procedió a recortar la mitad de columnas de la variable tipo arreglo para luego girar la segunda mitad de columnas, y posteriormente concatenarla con la primera mitad de columnas. La figura 13 muestra el procedimiento para las transformaciones geométricas de giro y mirror sobre dos imágenes (tonos de gris y color).

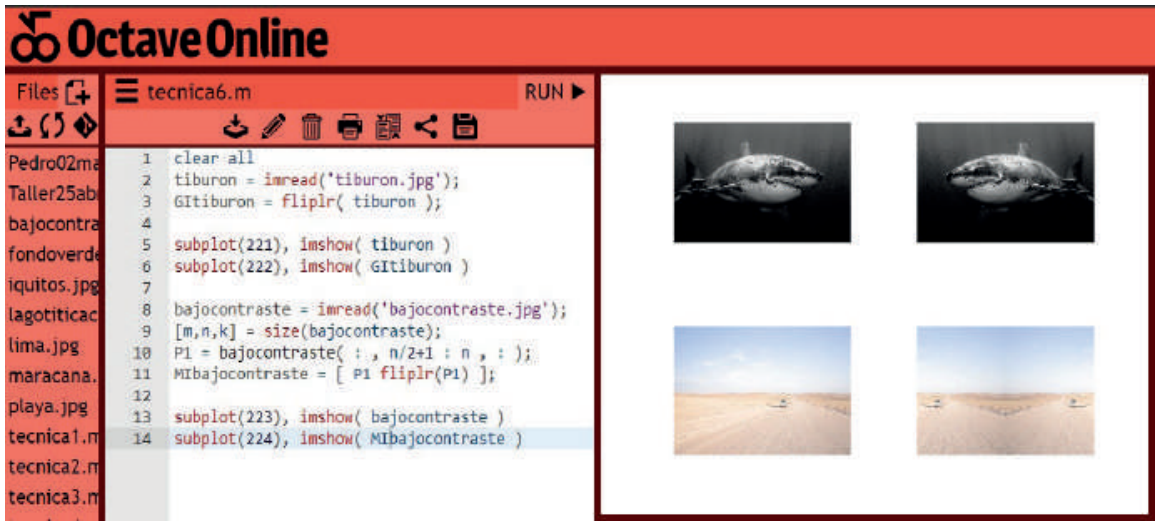

Figura 13. Transformaciones geométricas: Giro y Mirror utilizando el Octave-Online. Fuente: Elaboración propia.

3.7). Transformaciones geométricas: rotación y desplazamiento. La rotación, se determinó con apoyo del comando IMROTATE; para ello, fue necesario indicar el ángulo de rotación en forma horaria o anti-horaria. Y, en relación al desplazamiento, se optó por introducir un código de programación para desplazar la imagen a partir de una determinada fila y columna. La figura 14 muestra el procedimiento respectivo.

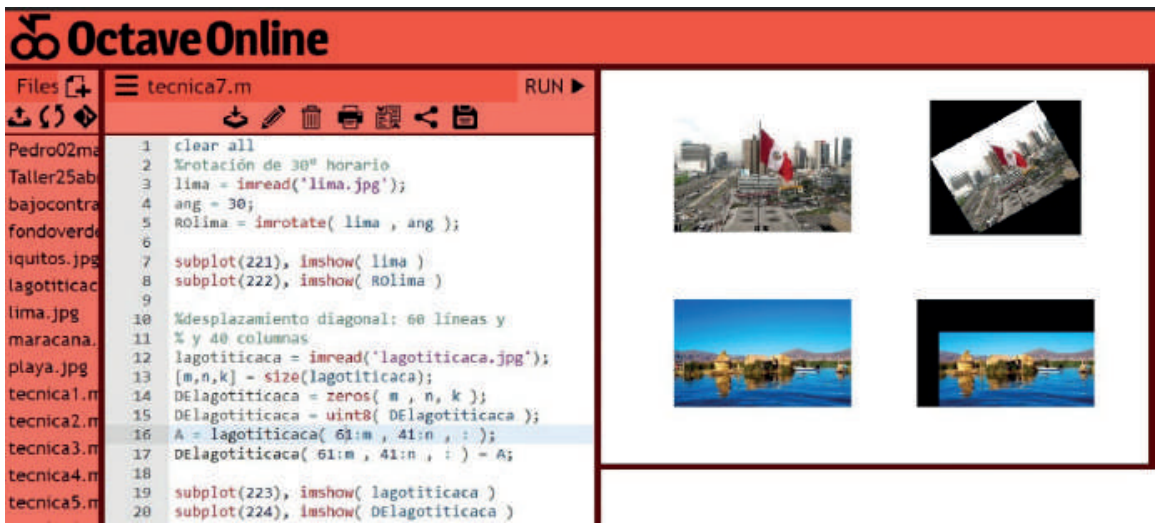

Figura 14. Transformaciones geométricas: rotación de 30 grados en sentido antihorario y desplazamiento de 60 líneas y 40 columnas, utilizando el Octave-Online.

Fuente: Elaboración propia. 
3.8). Aumento y disminución del brillo. En primer lugar, se eligió un valor constante. Luego, este valor fue sumado a todos los pixeles para aumentar el brillo y restado para disminuirlo. La figura 15 muestra el procedimiento de la aplicación del aumento y disminución del brillo en una imagen de color.

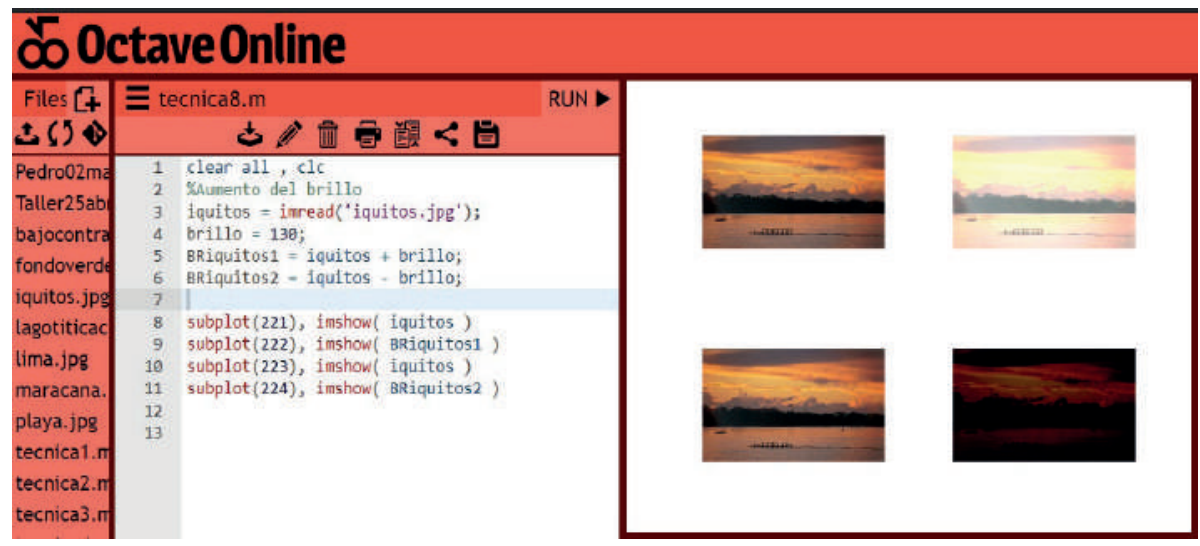

Figura 15. Aumento y disminución del brillo utilizando Octave-Online.

Fuente: Elaboración propia.

3.9). Manipulación del histograma. Debido a la variedad de formas de manipular el histograma, en este trabajo solamente se muestra un caso particular denominado expansión del histograma para mejorar el contraste. Para ello, se procede a utilizar un cálculo matemático mostrado en la figura 16, donde a la imagen se le resta el valor mínimo de su pixel y se la divide por una constante definida por la substracción del máximo y mínimo pixel de la misma.

3.10). Ecualización del histograma. Para la demostración de la ecualización se empleó una imagen con bajo contraste y el comando HISTEQ. Sin embargo, la aplicación se realizó sobre cada canal de color individualmente, obteniendo un histograma por separado tanto antes como después de la aplicación de la ecualización. La figura 17 muestra el procedimiento para la representación de la ecualización de una imagen con bajo contraste, y sus respectivos histogramas por cada canal de color.

\section{RESULTADOS}

Respecto a los resultados logrados en este artículo, a continuación, se describe una aplicación básica y práctica que reúne algunas de las técnicas de procesamiento de imágenes que han sido anteriormente desarrolladas. Tal aplicación se refiere al efecto Chroma-Key, donde se utiliza la separación de los canales de color, la umbralización, el negativo, la suma y multiplicación de imágenes, y la concatenación. Seguidamente, la figura 18, muestra el resultado de la aplicación 
de dicho efecto utilizando dos imágenes de color, donde la primera es aquella que contiene el fondo verde y de la cual se extrae al personaje (mujer), y la segunda es aquella que proporciona el nuevo fondo donde se inserta al personaje para formar una imagen fusionada.

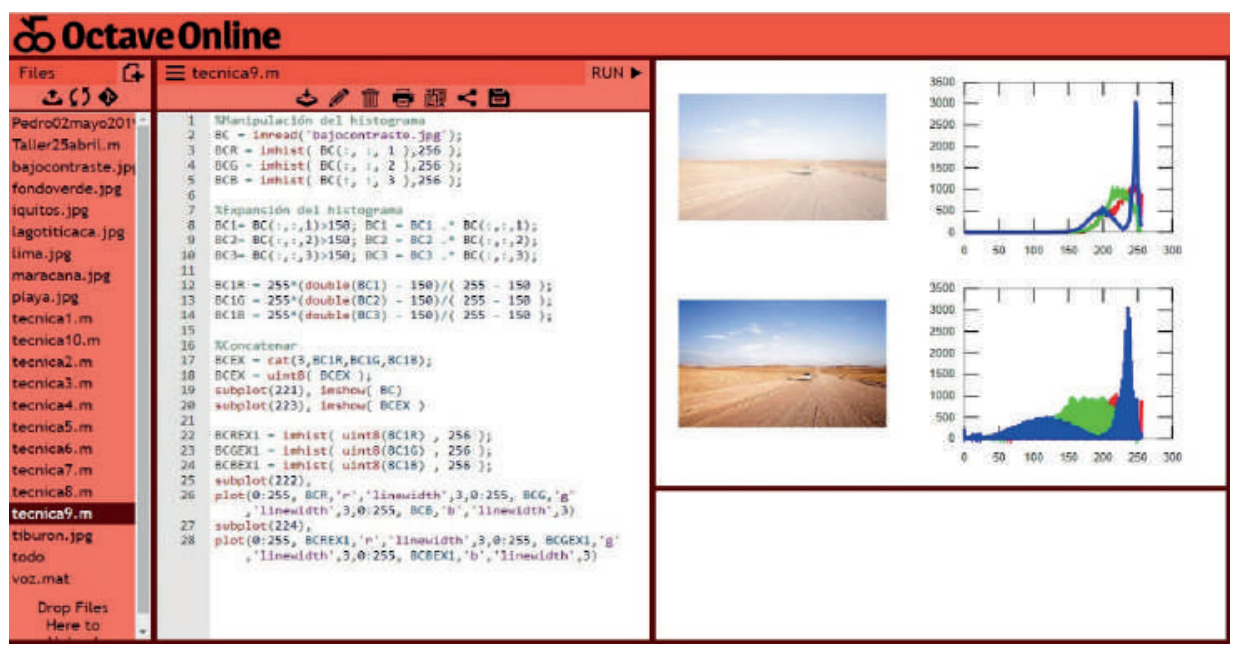

Figura 16. Expansión del histograma utilizando el Octave-Online. Fuente: Elaboración propia.

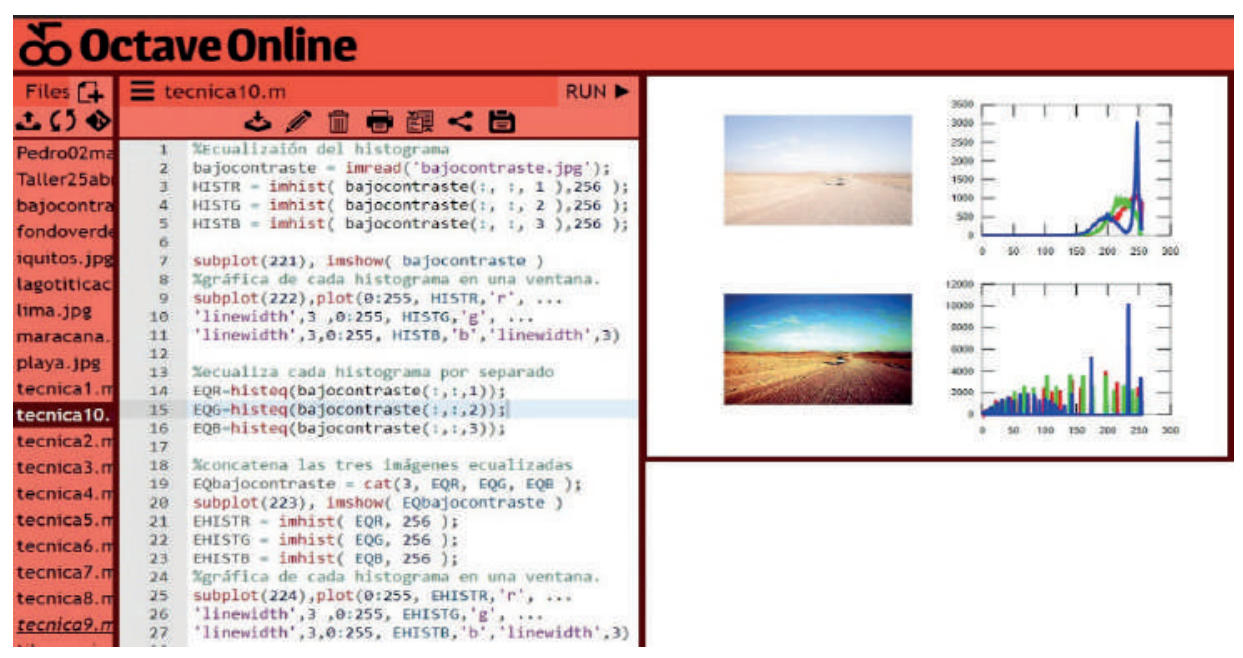

Figura 17. Ecualización del histograma de una imagen de color con bajo contraste, utilizando el Octave-Online.

Fuente: Elaboración propia. 


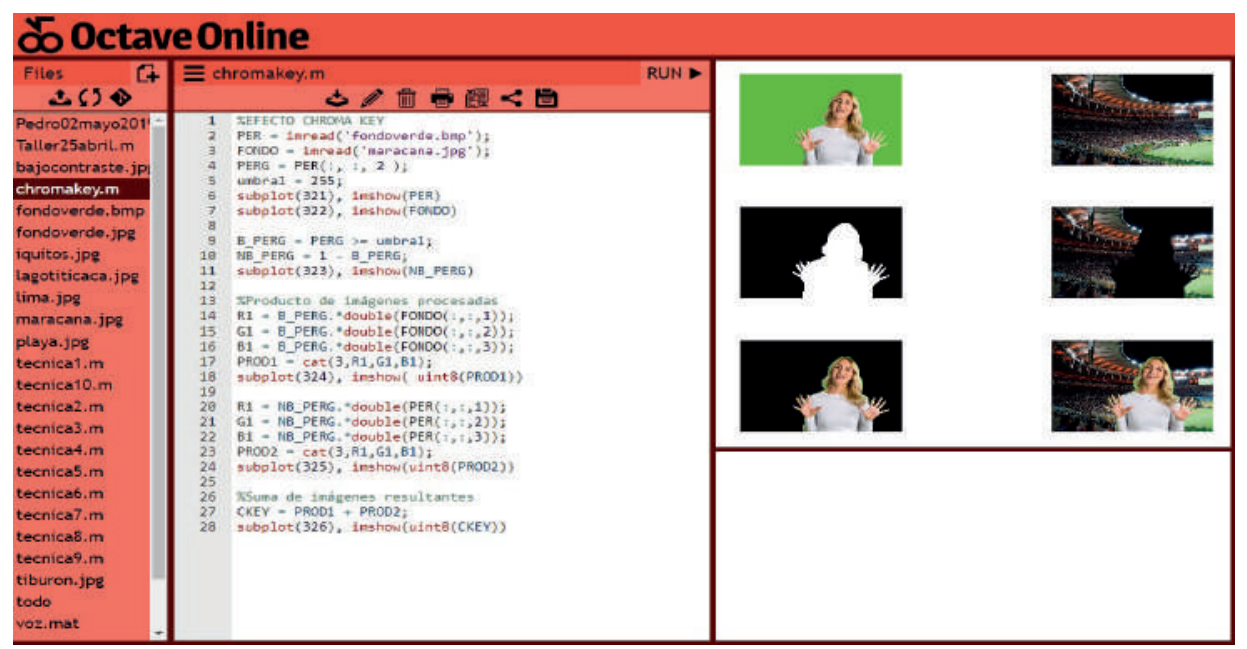

Figura 18. Resultado de la aplicación Chroma-Key utilizando el Octave-Online. Fuente: Elaboración propia.

\section{CONCLUSIONES}

El uso de la interfaz de usuario Web Octave-Online permitió realizar diez técnicas de procesamiento básico espacial en imágenes digitales, sobre un grupo de archivos JPG's con características particulares y acondicionadas a las técnicas propuestas. Además las expresiones matemáticas correspondientes a las técnicas desarrolladas en este artículo son ampliamente descritas en [11], [12], [13] y [14]. Asimismo, se mostró el código de programación empleado, los comandos utilizados y los resultados de las imágenes a través de comparaciones, por cada técnica desarrollada. Y así como también, se mostró la aplicación del efecto Chroma Key que reúne el uso de varias técnicas desarrolladas en este trabajo, aunque los resultados no fueron completamente positivos debido a la ausencia de los operadores morfológicos. Por lo cual, dicha interfaz facilitó la aplicación del procesamiento básico en imágenes digitales sin necesitar de un software licenciado, y empleando una programación simple y conocida tal como se utiliza en el software Matlab.

\section{REFERENCIAS BIBLIOGRÁFICAS}

[1] P. Huamaní, "Representation of Series and Transforms in engineering subject, using a Web User Interface for GNU Octave", in International Congress on Educational and Technology in Sciences CISETC, pp. 169-178, December 2019.

[2] Daviklis7 (2013, 22 abril). Animales tiburones blancos en escala de grises fondo de pantalla bajo el agua [Online]. Disponible: http://www.hdfondos. 
eu/imagen/219344/animales-tiburones-blancos-en-escala-de-grisesfondo-de-pantalla-bajo-el-agua

[3] G. Luijk (2008, 12 noviembre). Derecheo en escenas de bajo contraste [Online]. Disponible: http://www.guillermoluijk.com/article/ettr/index. htm

[4] D. Orihuela (2019, 27 agosto). Marcona: conoce la cuna de los pingüinos en Ica [Online]. Disponible: https://blog.redbus.pe/sin-categorizar/marconapinguinos-ica

[5] J. Moreno (2015, 15 abril). Las limitaciones tributarias a las inversiones peruanas en el extranjero [Online]. Disponible: https://ius360.com/ publico/tributario/las-limitaciones-tributarias-las-inversiones-peruanasen-el-extranjero/

[6] C. Banyuls. Pexels: una comunidad llena de talento que nos ofrece fotos increíbles totalmente gratis [Online]. Disponible: https://www.pexels.com/ es-es/foto/1912269/

[7] Daytours4u (2015, 13 agosto). Río 2016: Qué hacer en el Maracaná [Online]. Disponible: https://www.daytours4u.com/es/travel-guide/rdj4u/quehacer-en-el-maracana/

[8] Agencia de Viajes y Turismo MachuPicchu Travel. Lago Titicaca [Online]. Disponible: https://www.machupicchu.com.pe/lago-titicaca

[9] Peru.com (2015, 25 setiembre). Yarinacocha: Una laguna adornando la selva peruana (FOTOS) [Online]. Disponible: https://peru.com/viajes/conozcaperu/yarinacoha-laguna-adornando-selva-peruana-fotos-noticia-402963

[10] Octave Online. [Online]. Disponible: https://octave-online.net/

[11] O. Marques e H. Vieira. Gallager. Processamento Digital de Imagens. Rio de Janeiro: Brasport, 1999.

[12] E. Alegre, G. Pajares y A. Escalera. Conceptos y Métodos en Visión por Computador. España: Grupo de Visión del Comité Español de Automática, 2016.

[13] C. Reyes-Aldasoro. Biomedical Image Analysis Recipes in Matlab. For Life Scientists and Engineers. UK: Wiley Blackwell, 2015.

[14] K. Chi-Wah and T. Wing.Shan. Digital Image Interpolation in Matlab. Singapore: Wiley - IEEE PRESS, 2019. 